\title{
Simple Effective and Robust Weight Sensor for Measuring Moisture Content in Food Drying Process
}

\author{
Thadchapong Pongsuttiyakorn, ${ }^{1 *}$ Pitikhate Sooraksa, ${ }^{2}$ and Pimpen Pornchalermpong ${ }^{1}$ \\ ${ }^{1}$ Department of Food Engineering, Faculty of Engineering, King Mongkut’s Institute of Technology Ladkrabang, \\ 1 Chalongkrung, Ladkrabang, Bangkok 10520, Thailand \\ ${ }^{2}$ Department of Computer Engineering, Faculty of Engineering, King Mongkut's Institute of Technology Ladkrabang, \\ 1 Chalongkrung, Ladkrabang, Bangkok 10520, Thailand
}

(Received February 27, 2019; accepted May 29, 2019)

Keywords: weight sensor, load cell, food drying process, Kalman algorithm, moisture content

Measurement values using weight sensors are inherently contaminated by noise generated from electrical sources, thermal dynamics, mechanical vibration, and environmental conditions. In this paper, we present a method of correcting the accuracy of the sensors by using filtering algorithms. Two well-known methods in electrical engineering, namely, low-pass filtering and the Kalman algorithm, are applied to correct the real-time measured weight under various temperatures to determine moisture content during the food drying process. From an experiment using pineapples as the food material, the results showed the effectiveness of the application even if it has a simple design and is easy to implement. For small and medium enterprises (SMEs), the method and demonstration shown in this paper can be adopted and the proposed system is scalable for designing weight sensor systems operating in a thermal drying cabinet.

\section{Introduction}

Knowledge of moisture content plays a crucial role in all areas of the food industry and necessary to predict the behaviors of food during processing. ${ }^{(1-9)}$ During the drying process, moisture content in food materials can be measured from the mass of water in a known mass of sample. In doing so, the moisture content is calculated by measuring the weight of a food before and after the water is removed by evaporation. The accuracy of the calculation depends on the quality and physical limitation of weight sensors. ${ }^{(10)}$ Generally, the quality of the sensors depends on their price, which indicates the quality of the materials used in their parts and components.

Load cells are the most commonly used weight sensors in industry. A typical load cell consists of four strain gauges in a Wheatstone bridge configuration. The deformation of strain gauges changes the resistance proportionally to the strain, causing a change in electrical signals as outputs of the circuit. ${ }^{(10,11)}$ Practically, the measured signals can be contaminated

*Corresponding author: e-mail: tpsky.7@gmail.com https://doi.org/10.18494/SAM.2019.2347 
with electrical or thermal noises from the environment and the disturbance from mechanical vibration. Research studies on noise elimination have been carried out to achieve a higher accuracy. ${ }^{(12-16)}$ In this paper, the normal temperature range of a load cell given by its manufacturer is between -10 and $+40{ }^{\circ} \mathrm{C}$. Information about this low-cost weight sensor is not completely provided. The data sheet provides that noises will increase $0.017-0.02 \%$ per ${ }^{\circ} \mathrm{C}$. To illustrate the existence of noise, Fig. 1 shows a noise profile at $25^{\circ} \mathrm{C}$. However, in our case, the operating temperature is up to $70^{\circ} \mathrm{C}$, at which a higher noise occurs.

In food drying processes using heat convection, it is necessary to determine the rate of drying of the product with respect to time. ${ }^{(8,9,19)}$ This procedure requires opening and closing the oven or chamber periodically, which may result in measurement errors. To cope with this problem, a weight sensor is installed by hanging it outside a drying cabinet. ${ }^{(20,21)}$ However, this method needs to be modified for the industrial scale.

From the practical viewpoint, if we can put the weight sensors inside a drying chamber, it would be easy to determine the moisture content of food in real time. In reality, the materials used as components of load cells are deformed by temperature. ${ }^{(10,22,23)}$ As a result, the dynamic heat in the chamber during a multistep drying process causes the temperature to change accordingly yielding measurement errors. ${ }^{(24,25)}$ Evidently, the effects of temperature variations in the working environment ranging from -35 to $+80{ }^{\circ} \mathrm{C}$ on the weight of materials have been confirmed. ${ }^{(22)}$ Likewise, the effects of environmental temperature variations ranging from -40 to $+85{ }^{\circ} \mathrm{C}$ on the errors of weight sensors have also been reported. ${ }^{(1)}$

In this paper, we show how to enhance the accuracy of a low-cost weight sensor using a simple yet effective method of measuring moisture content during the food drying process. Two algorithms for minimizing errors of measurement are applied and the results are compared to validate the effectiveness of the proposed algorithms. On the basis of the result, a suitable low-pass filter will be adopted for measurement error correction in a real process for drying pineapples as described in the next sections. This paper is organized as follows. In Sect. 2, we provide a brief review of the filtering algorithms, drying process, and experiment. In Sect. 3, we present the results and discussion. In Sect. 4, we give the conclusion.

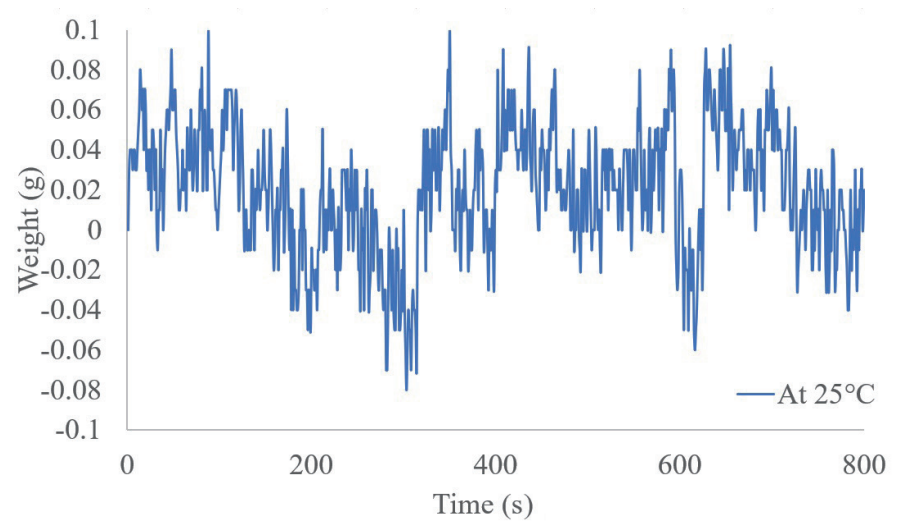

Fig. 1. (Color online) Noise profile of the load cell at $25^{\circ} \mathrm{C}$. 


\section{Materials and Methods}

\subsection{Load cell sensor}

The weight sensor in this paper is a single-point type designed to be used with a small platform. A small platform is defined as one that is used for weighing less than 1 ton. To obtain effective results, the load cell should be fixed at the center of the platform. In this paper, the load cell is a 61022-3KG-0000M model (Sensortronics, USA) made of aluminum with a maximum weighing capacity of up to $3 \mathrm{~kg}$. The temperature can be measured in the range from 0 to $70{ }^{\circ} \mathrm{C}$ with $3.0 \mathrm{mV} / \mathrm{V}$ in full-scale output (FSO) signals. Figure 2 shows a schematic diagram of the components and installation configuration.

\subsection{Statistical model}

For data collection, signals from strain gauges are sent to an Arduino Mega 2560 microcontroller via an HX711 signal amplifier. The weight can be calculated using the formula

$$
W(t)=(V-Z) / C,
$$

where $W(t)$ is the weight from the measurement $(\mathrm{g}), V$ is the signal voltage sensed by the weight sensor $(\mathrm{mV}), Z$ is a correcting variable for the signal $(\mathrm{mV})$, and $C$ is a correcting factor for measurement accuracy. Equation (1) can be improved by considering the effects of temperature on the measurement. We then obtain the following equations:

$$
\begin{gathered}
W(t)=\left(V-Z_{T}-e_{T}\right) / C, \\
x=T-T_{0}, \\
e_{T}=y=a_{0} x^{1}+a_{1} x^{2}+a_{2} x^{3}+a_{3} x^{4}+\cdots+a_{n} x^{p}+b,
\end{gathered}
$$

where $Z_{T}$ is $Z$ at the measured temperature $T, y$ or $e_{T}$ is an error signal at $T, T_{0}$ is a known calibration temperature, and $x$ is the difference between the initial temperature and the
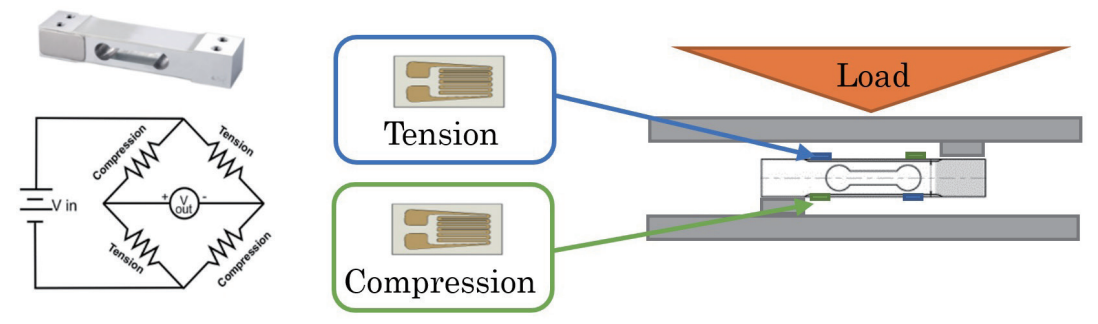

Fig. 2. (Color online) Schematic diagram of the components and installation configuration of a single-point load cell. 
measured one. By using the regression equation, Eq. (4), with a set of standard weights for calibration consisting of 200, 1000, and $2000 \mathrm{~g}$ for 1000 data points, we can determine the coefficients of regression, $a_{i}$ and $b_{i}$, where $i=0,1, \ldots, n$.

\subsection{Filter}

Eliminating noises in the measurement system is necessary to increase the measurement accuracy. In other words, all communication systems need sensing signals with a high signal-to-noise $(\mathrm{S} / \mathrm{N})$ ratio. ${ }^{(26-28)}$ This can be achieved by implementing filters in the system. In this work, we use a low-pass filter (LPF) and a Kalman filter (KF) for filtering unwanted noises generated by the thermal dynamics of the drying system owing to the placement of the weight sensors inside the oven cabinet.

\subsubsection{LPFs}

In engineering practice, the first algorithm to try is a simple low-pass finite impulse response (FIR) filter commonly used for smoothing an array of sampled data obtained from the weight sensor. In the time domain, this is called the moving average filter. This filter is not only very good for many applications, but it is an optimal one because it reduces random white noise while maintaining the sharpest step response. In addition, the equation is very simple:

$$
y[i]=(1 / M) \sum_{j=0}^{M-1} x[i+j],
$$

where $M$ is the number of data points on average, $y[]$ is the output signal, and $x[]$ is the input signal from the weight sensor.

\subsubsection{KFs}

The second algorithm to try is one of the best estimation methods, namely, the use of a KF. Unlike an LPF, a KF has some advantages over the moving average filter in the sense that it can be a smoother, filter or predictor. By defining the filter in a state space form, at the discrete time $k$ and previous time $k-1$, we can easily implement the filter in two main parts, which are prediction and the update of prediction values. ${ }^{(29-31)}$ The algorithmic loop is summarized in three steps as follows. Note that, in our case, we use a single measured value for real-time weight measurement and calculation:

$$
\begin{gathered}
\text { Calculate Kalman Gain: } K(k)=[P(k)+R(k)]^{-1}, 0 \leq K(k) \leq 1, \\
\text { Update Current Estimate: } X(k)=X(k-1)+K(k)[W(k)-X(k-1)] \text {, }
\end{gathered}
$$


Update New Error in the Estimate: $P(k)=P(k-1)[(1-K(k))]$.

Here, $K$ is the Kalman gain, $P$ is the error in estimate, $R(k)$ is the error in measurement, $W$ is the measurement value from the weight sensor, and $X$ is the estimated weight.

\subsection{Drying process}

The drying process is a food preservation method that has been used for a long time. It uses the principle of heat transfer and mass dehumidification of food by removing most water molecules in food as shown in Fig. 3. As can be seen in Fig. 3, hot air transfers heat to the material that it passes through. The preservation is based on the fact that pathogens cannot grow if a product has a water activity $\left(a_{w}\right)$ below $0.60 .^{(8,9,19)}$ In addition, hot air will transfer heat to the material that it passes through. Eventually, the volume of the material decreases, making the food lighter and more convenient for transportation and consummation or use as raw materials for further processing.

\subsubsection{Moisture content}

Moisture content is important because it affects the quality and storage of dried food products. Moisture content can be determined from the weight of the food material, which changes during the drying process. The weight of the material is measured using the weight sensor. The moisture content of a sample in each period can be calculated using the equation

$$
M_{t}=\left(W_{t}-W_{s}\right) / W_{s}
$$

where $M_{t}$ is the sample moisture in each period at time $k$ ( $\mathrm{kg}$ water $/ \mathrm{kg}$ dry solid), $W_{t}$ is the total weight of the sample at each time interval $(\mathrm{kg})$, and $W_{S}$ is the solid weight of the sample $(\mathrm{kg})$, which is constant.

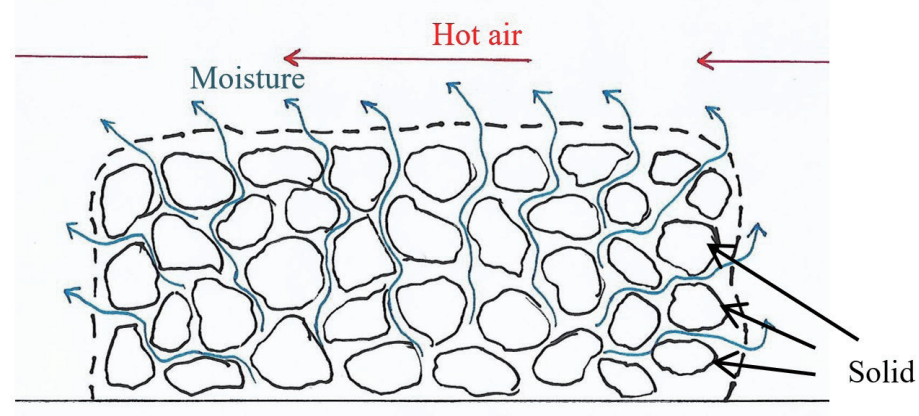

Fig. 3. (Color online) Moisture movement during the drying process. 


\subsubsection{Drying rate}

The drying rate of the process can be calculated from the liquid mass evaporated per evaporation area per time as

$$
R_{a}=-\left(W_{s} / A\right)(d m / d t),
$$

where $R_{a}$ is the drying or evaporation rate $\left(\mathrm{kg} / \mathrm{m}^{2} \mathrm{~h}\right), A$ is the surface area of evaporation $\left(\mathrm{m}^{2}\right)$, $W_{S}$ is the solid weight of the sample $(\mathrm{kg})$, and $d m / d t$ is the mass of water that evaporates per unit time $(\mathrm{kg} / \mathrm{h})$.

\subsection{Drying experiment}

An actual experiment is conducted in the drying process using smooth cayenne pineapple as the product. The shell is sliced to a thickness of $3 \mathrm{~mm}$ for each sample and cut into four quarters. For control parameters, the product surface temperature is set at $60{ }^{\circ} \mathrm{C}$ (dry in the air dryer) and the air flow speed is $1.3 \mathrm{~m} / \mathrm{s}$. Then, the product is dried until its wet basic moisture is $9 \%$ (the desired value). The initial air temperature in the cabinet is set at $70{ }^{\circ} \mathrm{C}$. Data on air temperature, product surface temperature, and weight are recorded every minute until the end of the process.

\section{Results and Discussion}

The environmental condition of the experiment and the control parameters used in the experiments are based on Sect. 2.5. Three experiments were carried out and results are presented in Sects. 3.1-3.3. In Sect. 3.1, we show the calibration of the converted values of the electrical voltage signals into weight with temperature compensation. In Sect. 3.2, we compare the performance charcteristics between the LPF and the KF. In the last subsection, Sect. 3.3, we show the experimental results of the application of the weight sensors in the drying process.

\subsection{Test for statistical model}

In this subsection, we discuss the calibration of the weight change due to temperature effects. The standard weights measured at $25{ }^{\circ} \mathrm{C}$ are 200,1000 , and $2000 \mathrm{~g}$. The readers may refer to Sect. 2.2 for calibration formulas and the statistical model. The average value that makes the electrical signal become zero $\left(Z_{T}\right)$ is 8603554 (Hex) and the average value of the correcting factor that makes the weight reading correct $(C)$ is 734.76862 . Figure 4(a) shows the load cells used in this experiment with standard weights. After unit conversion, it is found that the signals at 24 to $70{ }^{\circ} \mathrm{C}$ in Fig. 4(b) have gained maximum errors of about $9 \%$ by weight. This means that, if the actual weight is $100 \mathrm{~g}$, the measured weight may be about $109 \mathrm{~g}$. By polynomial regression with temperature compensation, we obtain the coefficients as shown in Table 1. From Fig. 5, it is clear that the polynomial regression is best fitted up to the 3rd-order 


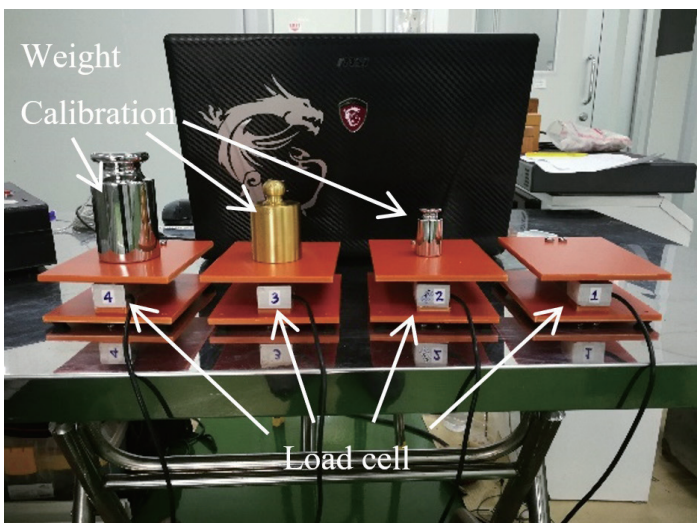

(a)

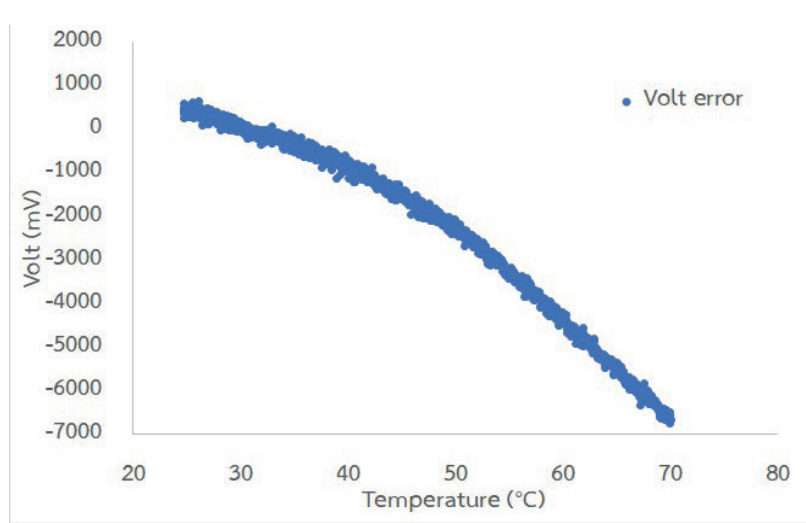

(b)

Fig. 4. (Color online) (a) Standard weights and load cells and (b) voltage signal versus temperature.

Table 1

Regression coefficients of various $n$th polynomial regressions with temperature compensation.

\begin{tabular}{lccccc}
\hline & Polynomial 2nd & Polynomial 3rd & Polynomial 4th & Polynomial 5th & Polynomial 6th \\
\hline$R^{2}$ & 0.9981 & 0.9981 & 0.9985 & 0.9985 & 0.9985 \\
a1 & 75.367 & 0.0056 & -590.67 & -324.91 & 15.709 \\
a2 & -2.4624 & -3.248 & 20.821 & 8.5232 & -9.5046 \\
a3 & 0 & 0.0056 & -0.3474 & -0.0716 & 0.4748 \\
a4 & 0 & 0 & 0.0019 & -0.0011 & -0.0102 \\
a5 & 0 & 0 & 0 & 0.00001 & 0.00009 \\
a6 & 0 & 0 & 0 & 0 & -0.0000003 \\
b & 52.91 & -437.19 & 6904.1 & 4679.7 & 2527.2 \\
\hline
\end{tabular}

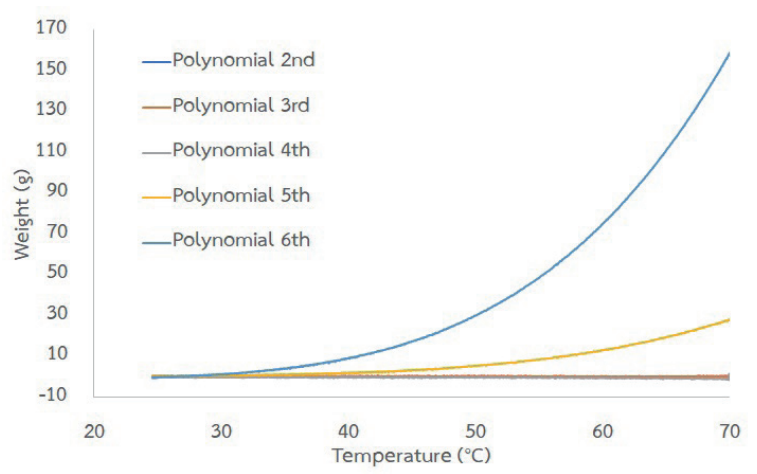

Fig. 5. (Color online) Voltage error signals after temperature compensation.

polynomial. As can be seen from Table 1, the correct statistical model for load cells in this experiment is in the form of the 3rd-order polynomial regression.

\subsection{Performance tests for the filters}

In this study, performance comparison tests between the LPF and the KF discussed in Sect. 2.3 are carried out. For the LPF, we use $M=10$ with a sampling time of $0.1 \mathrm{~ms}$ for each single 
signal. For the KF, the initial parameters are $R=0.129092915$ and $P=0.0001$. As described in Sect. 3.1, other conditions are set by varying temperature ranging from 25 to $70{ }^{\circ} \mathrm{C}$ and collecting data up to $1800 \mathrm{~s}$. Figure 6(a) shows the performance characteristics of both filters. As can be seen, both filters yield similar results. This could happen because both filters are optimal for minimizing least square errors they behave like a signal smoother. It is also clear that, in this application, a moving average algorithm is adequate yet simple, effective, and easy to implement. As shown in Fig. 6(a), results indicating the weights at various temperatures ranging from 25 to $70{ }^{\circ} \mathrm{C}$ are accurately measured within an acceptable $0.1 \mathrm{~g}$ error tolerance. In addition, Fig. 6(b) shows signals of different weights measured at various temperatures using the LPF. This shows the robustness of the proposed adjustment algorithm.

\subsection{Drying experiment}

In the previous section, we showed lab-scale tests for calibration and filter selection for software development for signal and data processing. We then used the optimal parameters and the LPF in a real environment shown in Fig. 7. The evaporative cabinet in Fig. 7 was built by

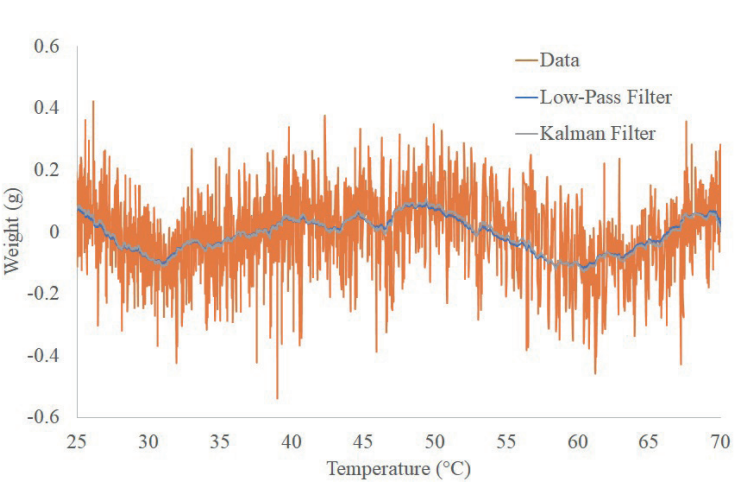

(a)

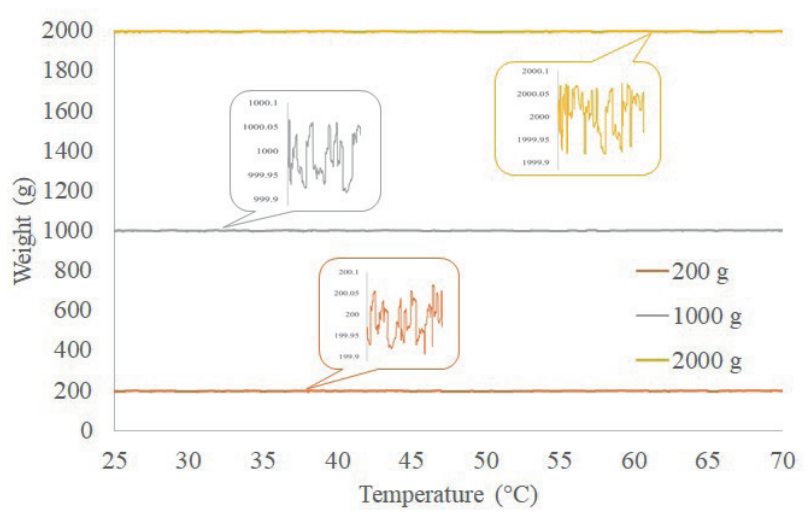

(b)

Fig. 6. (Color online) Robustness of the adjustment algorithm within $0.1 \mathrm{~g}$ tolerance. (a) Comparison of signals using raw data: LPF and KF. (b) Comparison of signals obtained from various weights at different temperatures.
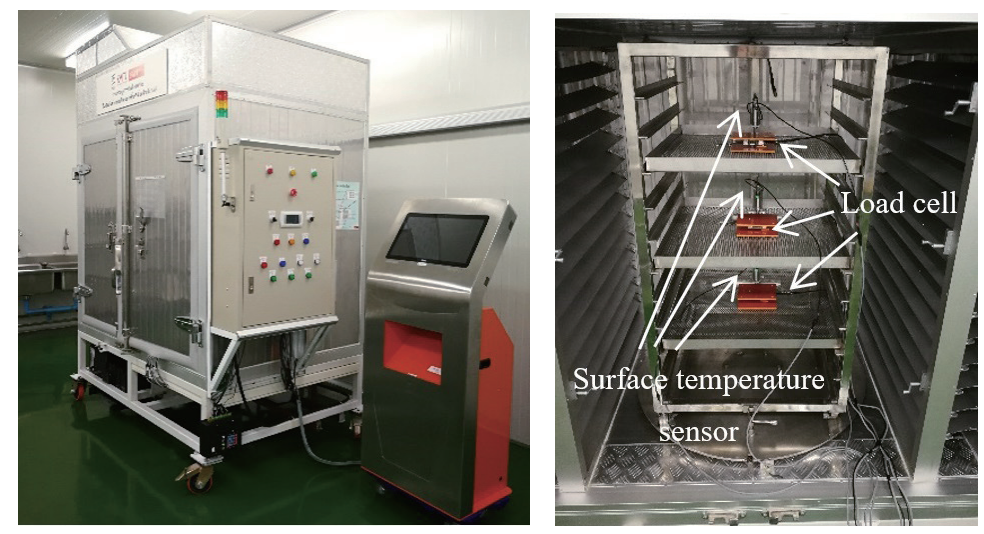

Fig. 7. (Color online) Dryers installed with weight sensors. 
the authors using heat pump technology combined with oven functions for high-temperature operation between 30 and $70{ }^{\circ} \mathrm{C}$. In this experiment, the system is equipped with surface temperature and weight sensors for collecting the data. Figure 8 shows sliced pineapples as the food material for testing in the setup experiment. On the basis of Sects. 2.4 and 2.5, Figs. 9 and 10 yield satisfactory results, that is, the weights at various temperatures are

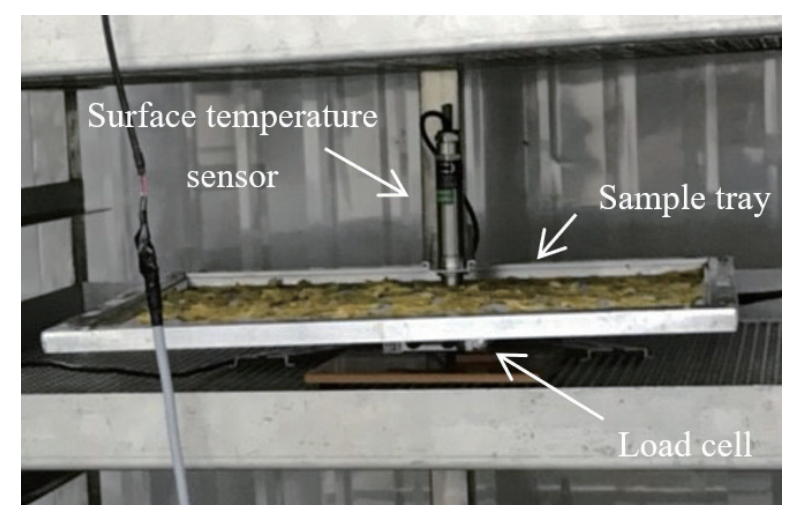

Fig. 8. (Color online) Location of the weight sensor during the drying process.

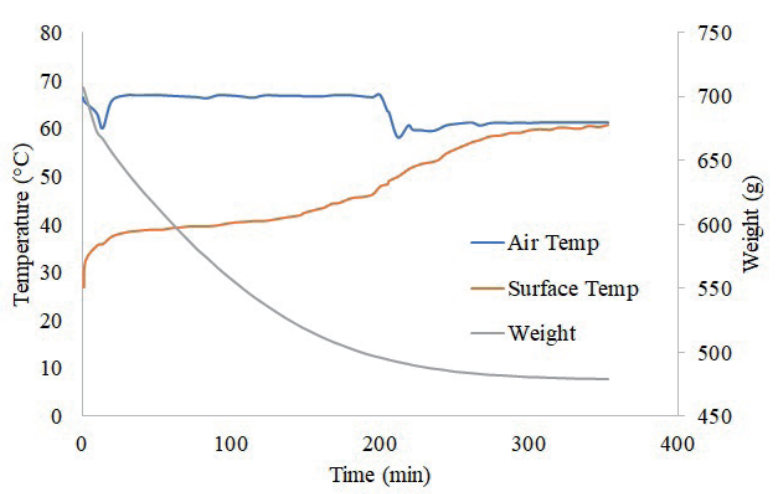

(a)

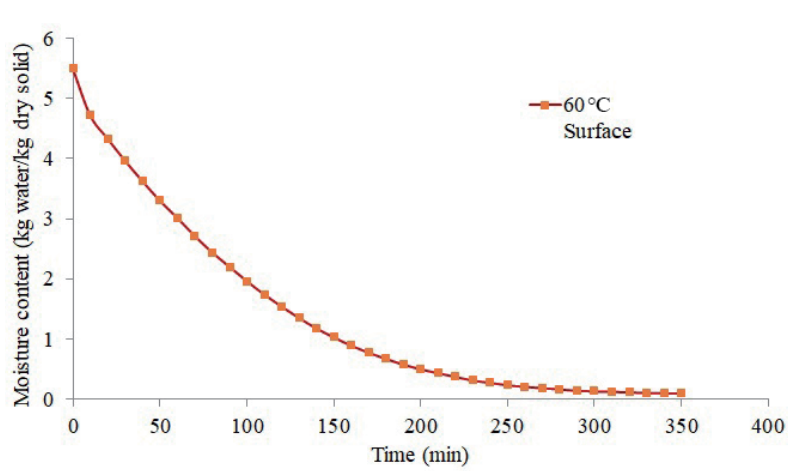

(b)

Fig. 9. (Color online) (a) Changes in air temperature, surface temperature, and weight during drying of pineapples. (b) Moisture content (dry base) of products per drying period.

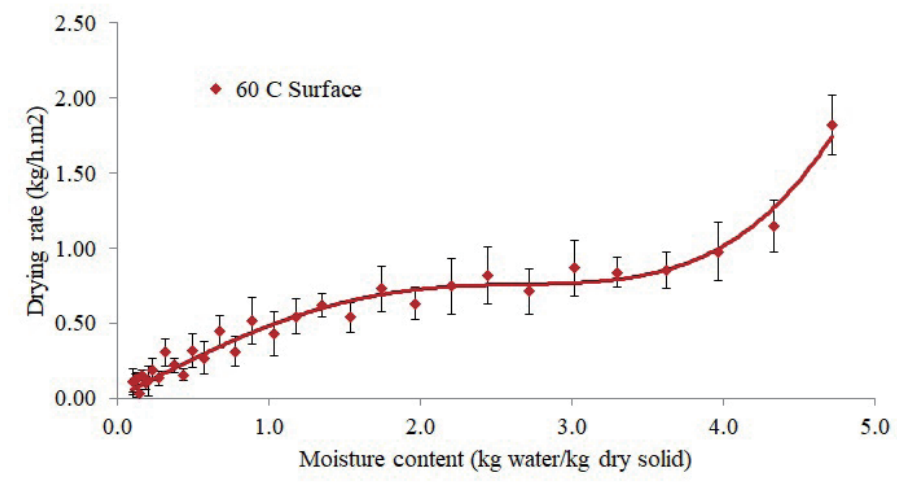

Fig. 10. (Color online) Drying rate per moisture content (dry basis) during drying of pineapple. 
accurately measured within an acceptable tolerance, which again shows the robustness of the proposed adjustment algorithm. The weight results can be used in the calculation of the moisture content in Fig. 9(b) and the drying rate in Fig. 10. Intuitively, the shapes of the moisture content and drying rate curves appear to be regular, implying that the results met the objective of this work. In fact, we manually verified the accuracy of the results by repeating the weight measurement of the final products, and the findings confirmed that the final products have weights within a $0.1 \mathrm{~g}$ tolerance.

\section{Conclusion}

In this study, we design and construct a practical, simple, easy method of calibrating weight sensors with unwanted signals filtered for food drying processes. For calibration, the statistical model in this work reveals that the third-order polynomial regression is adequate for compensating for the effects of temperature on the statistical model of the load cell. The signal filtering results obtained using a simple LPF in the time domain are as good as those obtained using a KF in this study. This implies that the implementation of an LPF is adequate for weight measurement compensation in a food drying process.

\section{Acknowledgments}

This study was supported in part by Thailand Research Funds (RDG6050003) and Center for Robotics and AI, King Mongkut's Institute of Technology Ladkrabang (KREF036205).

\section{References}

1 Y. Fujimoto, H Chiba, R. Okawa, and K. Toko: Sens. Mater. 27 (2015) 365. https://doi.org/10.18494/ SAM.2015.1099

2 J. Liang, J. Zhang, P. Wang, C. Liu, S. Qiu, and T. Ueda: Sens. Mater. 28 (2016) 201. https://doi.org/10.18494/ SAM.2016.1281

3 Y. Sun, H. Gu, Z. Wei, and H. Xu: Sens. Mater. 30 (2018) 1947. https://doi.org/10.18494/SAM.2018.1811

4 J. Johnston and K. Coffey: Sensors 17 (2000) 1. http://ebook.pldworld.com/_Semiconductors/Cirrus\%20 Logic/2002\%20Product $\% 20$ Guide/pubs/SEN5243x.pdf

5 M. A. Hannan, A. Hussain, and S. A. Samad: Sens. Mater. 23 (2011) 179. https://doi.org/10.18494/ SAM.2011.694

6 M. Halimic and W. Balachandran: Proc. 1995 IEEE Int. Symp. Industrial Electronics (IEEE, 1995) 786. https:// doi.org/ 10.1109/ISIE.1995.497286

7 A. M. Harb: Proc. Islamic University (2013). https://library.iugaza.edu.ps/thesis/112429.pdf

8 P. Pietrzak, M. Meller, and M. Niedźwiecki: Proc. Mechanical Systems and Signal Processing 48 (Elsevier, Amsterdam, 2014) 67. https://doi.org/10.1016/j.ymssp.2014.02.013

9 W. Hernandez: Sensors 6 (2006) 697. https://www.ncbi.nlm.nih.gov/pmc/articles/PMC3894532/pdf/ sensors-06-00697.pdf

10 H. Nanto, Y. Hamaguchi, M. Komura, Y. Takayama, T. Kobayashi, Y. Sekikawa, T. Miyatake, E. Kusano, T. Oyabu, and A. Kinbara: Sens. Mater. 14 (2002) 001. https://myukk.org/SM2017/sm_pdf/SM465.pdf

11 J. Zhu, Z. Zhu, Z. Lai, R. Wang, X. Wu, G. Zhang, and Z. Zhang: Sens. Mater. 14 (2002) 209. https://myukk. org/SM2017/sm_pdf/SM483.pdf

12 I. J. Kim, S. D. Han, I. Singh, H. D. Lee, and J. S. Wang: Sens. Mater. 17 (2005) 219. https://myukk.org/ SM2017/sm_pdf/SM600.pdf

13 S. Etoh, L. Feng, K. Nakashi, K. Hayashi, A. Ishii, and K. Toko: Sens. Mater. 20 (2008) 151. https://doi. org/10.18494/SAM.2008.532 
14 Y. Hasegawa, G. Yamanaka, K. Ando, and H. Uchida: Sens. Mater. 26 (2014) 461. https://doi.org/10.18494/ SAM.2014.1008

15 M. Yasuura, Q. Shen, Y. Tahara, R. Yatabe, and K. Toko: Sens. Mater. 27 (2015) 351. https://doi.org/10.18494/ SAM.2015.1086

16 D. Richiedei and A. Trevisani: Proc. Mech. Syst. Signal Process. 98 (2018) 281. https://doi.org/10.1016/ j.ymssp.2017.04.049

17 A. Mujumdar and S. Devahastin: Mujumdar's Practical Guide to Industrial Drying (Thananuch Business, Bangkok, 2000).

18 T. Kudra and A. Mujumdar: Advanced Drying Technology (CRC Press, Florida, 2009) 2nd ed.

19 S. Phoungchandang and S. Saentaweesuk: Proc. Food Bioprod. Process. 89 (2018) 429. https://doi.org/10.1016/ j.fbp.2010.07.006

20 S. Eleeyah, S. Fameera, and H. Radchadaporn: Proc. J. Yala Rajabhat University (2012) 105. http://research. yru.ac.th/e-journal/index.php/journal/article/view/27

21 A. Rittichai: Proc. Thai Society of Agricultural Engineering J. 22 (TSAE, Bangkok, 2016) 28. https://www.tcithaijo.org/index.php/TSAEJ/article/view/68894/56086

22 G. E. David and P. R. Edgar: Proc. Int. Conf. Cultivating Metrological Knowledge (2007) 17. www.imeko.org/ publications/tc3-2007/IMEKO-TC3-2007-017u.pdf

23 V. Matko: Sens. Mater. 16 (2004) 1. https://myukk.org/SM2017/sm_pdf/SM543.pdf

24 S. Cernîşev: Proc. J. Food Eng. 96 (2010) 114. https://doi.org/10.1016/j.jfoodeng.2009.07.002

25 A.-M. Nuñez Vega, B. Sturm, and W. Hofacker: Proc. J. Food Eng. 170 (2010) 16. https://doi.org/10.1016/ j.jfoodeng.2015.08.033

26 A. Ueno, T. Yamaguchi, T. Iida, Y. Fukuoka, Y. Uchikawa, and M. Noshiro: Sens. Mater. 24 (2012) 335. https:// doi.org/10.18494/SAM.2012.787

27 H. C. Yu, C. L. Cheng, P. H. Wu, and S. J. Li: Sens. Mater. 29 (2017) 885. https://doi.org/10.18494/ SAM.2017.1545

28 S. H. Han, M. H. Ryu, and J. N. Kim: Sens. Mater. 30 (2018) 1787. https://doi.org/10.18494/SAM.2018.1861

29 X. Cai, C. Zhang, S. Gao, L. Wang, and X. Li: Sens. Mater. 29 (2017) 1. https://doi.org/10.18494/ SAM.2017.1331

30 L. Mo, C. Li, H. Huang, and Y. Dong: Sens, Mater. 30 (2018) 1039. https://doi.org/10.18494/SAM.2018.1885

31 C. B. Fu, S. Gan, X. P. Yuan, and A. H. Tian: Sens. Mater. 30 (2018) 2577. https://doi.org/10.18494/ SAM.2018.2067

\section{About the Authors}

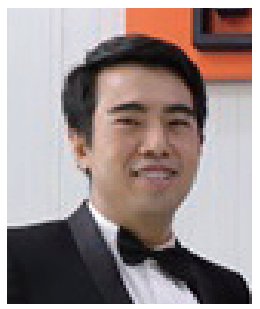

Thadchapong Pongsuttiyakorn received his B.E. and M.E. degrees from King Mongkut's Institute of Technology Ladkrabang (KMITL), Thailand in 2010 and 2013, respectively. From 2013 to 2015, he was an employee of Address and Huntz Co., Ltd., Thailand. He is currently a doctoral candidate of the Department of Food Engineering, Faculty of Engineering, KMITL. His research interests are in drying processes, food control, food engineering, and sensors. (tpsky.7@gmail.com)

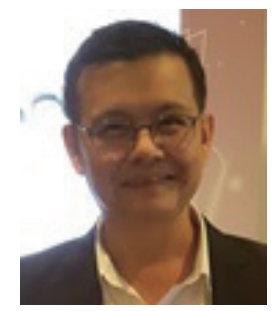

Pitikhate Sooraksa received his B.Ed. (Hons.) degree from Srinakharinwirot University, Patumwan, Thailand, in 1988, and his M.Sc. (Electrophysics) and Ph.D. (EE) degrees from George Washington University, Washington DC, and University of Houston, Texas, USA, in 1993 and 1996, respectively. From 1997 to the present, he has been working at KMITL, Thailand. His current research interests are in robotics and artificial intelligence with applications. (pitikhate.so@kmitl.ac.th) 


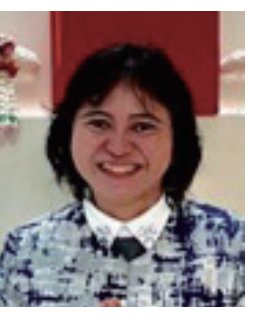

Pimpen Pornchaloem received her B.S. and M.S degree in product development from Kasetsart University, Thailand, in 1987 and 1989, respectively, and her Ph.D. degree from the Food Science and Human nutrition (Food Science) University, Florida, USA, in 1999. Since 2010, she has been an assistant professor at KMITL, Thailand. Her research interests are in the thermal processing of food design, the development of food processing, the effect of processing on food quality, and engineering properties of food. (pornchaloem.food@gmail.com) 